\title{
Interseccions entre imatge, art i tecnologia per a la construcció de coneixements sensibles
}

\author{
Ricard Ramon*
}

\section{Resum}

Aquest article desenvolupa una anàlisi al voltant de les connexions i les repercussions històriques entre la imatge fotogràfica i l'evolució de les noves tecnologies de la informació i la comunicació, amb la finalitat d'establir la capacitat de la fotografia artística per a crear pensament i coneixement, i esdevindre així en un dels mitjans educatius més rellevants de la cultura contemporània. Estableix els posicionaments del pensament humanista respecte a aquestes evolucions tecnològiques i el paper de la fotografia artística com a articuladora de pensament crític alternatiu al discurs textual. Analitza dins aquesta evolució històrica recent la importància de la fotografia en la mateixa evolució de la tecnologia i els possibles impactes en la cultura contemporània i en la configuració del pensament i l'imaginari del món. Finalment analitza la importància i la connexió que la fotografia, en relació amb la tecnologia, estableix amb les arts i l'estètica i el paper d'aquesta última com a articuladora de processos de creació de coneixement, a través de la imatge.

\section{Paraules clau}

Fotografia, educació artística, tecnologia, humanitats digitals, pedagogies visuals.

Recepció original: 30 de gener de 2020

Acceptació: 23 d'abril de 2020

Publicació: 30 de juny de 2020

\section{Introducció}

El present article planteja una anàlisi al voltant de les relacions existents entre les diferents formes tecnològiques vinculades a la creació, captació i registre d'imatges, especialment la fotografia. Aquestes relacions vénen a articular tot un seguit d'experiències associades a l'aprenentatge a través de les tecnologies de la informació i la comunicació que anomenem com a pedagogies visuals. Aquestes, permeten el desenvolupament de noves formes de construcció de pensament associades precisament a aquestes tecnologies, a l'ús que en fem d'elles i a l'impacte que tenen en el desenvolupament de noves formes d'aprenentatge i de construcció de coneixement. Tota una sèrie d'experiències i accions, amb un desenvolupament conceptual, que no deixa d'estar igualment vinculat a la tradició de les humanitats, dins un marc clàssic de pensament.

És impossible per part dels humans comprendre i aprendre de manera directa el món en tota la seva complexitat i extensió sense alguna forma de mediació. Necessitem instruments de mediació que intervinguin sobre la complexitat del món, que ens ajuden a assimilar i incorporar aquesta complexitat a la nostra comprensió global i a la nostra construcció com a persones inserida en aquest món. Totes les experiències educatives són en definitiva una forma de mediació entre nosaltres i la mateixa complexitat de la realitat en la qual estem immersos. També entre nosaltres i la comprensió del nosaltres, que tampoc

$\left.{ }^{*}\right) \quad$ Professor a la Facultat de Magisteri de la Universitat de València i Investigador de l'Institut Universitari de Creativitat i Innovacions Educatives. Doctor per la Facultat de Filosofia i Ciències de l'Educació de la UV, Llicenciat en Història de l'Art, Llicenciat en Belles Arts i Máster en Gestió Cultural. Adreça electrònica: ricard.ramon@uv.es 
és possible sense un procés de mediació. En aquest sentit, l'ús de les tecnologies com a instruments de mediació entre l'ésser humà i el món i l'entorn que l'envolta, a més de com a forma de coneixement propi, és també potencialment una pràctica i una experiència amb grans possibilitats pedagògiques.

El cos humà ja té en si mateixa una sèrie de mitjans de mediació i aprehensió de l'entorn i del món, que el cervell s'encarrega de sintetitzar, creant abstraccions que puguin ser assimilables per nosaltres. És evident, per tant, que l'educació és un procés de mediació, de síntesi i d'abstracció de la realitat per fer-la comprensible. Davall aquests paràmetres, les arts i la tecnologia es presenten com a extensions perfectes per a ampliar i desenvolupar les nostres capacitats de mediació, síntesi i abstracció sensible del món de cara a la seva major comprensió.

Així doncs, establirem una anàlisi de la forma amb la qual una de les expressions artístiques més vinculades amb el desenvolupament de les noves tecnologies, com és la fotografia, s'articula com a àmbit de mediació per a l'aprenentatge i la comprensió global del món. Tot allò a partir del concepte de pedagogies visuals, valorant les possibilitats que implica també com a instrument de creació de pensament i de coneixement complex.

\section{Tecnologia digital versus humanitats, o la necessitat de crear alian- ces educatives per afrontar les emergències del futur. L'art i la imatge com a mediadors}

Els avanços en la tecnologia escriuen una nova versió del món. A cada nou desenvolupament ens enfrontem a una revisió del nostre paper com a éssers humans. Això implica revisions antropològiques i filosòfiques permanents i ràpides, el que obliga al pensament a estar sempre alerta per tractar de repensar-nos en funció de la nostra relació amb la tecnologia. La tecnologia, especialment la digital, que és la que sofreix canvis de forma més ràpida i constant, manté un ritme que difícilment el desenvolupament del pensament crític pot assolir. Aleshores, ens enfrontem a un dilema de difícil resolució que ens situa davall un fet amb el qual el desenvolupament del pensament humanista té dues opcions. La primera, tractar de seguir responent teòricament a l'evolució dels avanços tecnològics. No obstant això, aquesta resposta implica el fet que sempre arribarem amb retard, donat que una nova onada de canvis hauran començat ja a desenvolupar-se i tornar a canviar les nostres formes de relació amb el món quant els teòrics comencen a donar resposta crítica a les anteriors formes, que ja apareixeran com a desfasades. Com ens recorda Lévy (2007):

Muy a menudo, en el momento en que deliberamos sobre una tecnología dada, ya se han impuesto ciertas maneras de hacer. Antes de que tomemos conciencia, la dinámica colectiva ha cavado sus surcos. Cuando se atrae nuestra atención, ya es demasiado tarde... mientras nos seguimos interrogando, otras tecnologías emergen en la frontera nebulosa donde se inventan las ideas, las cosas y las prácticas. (p. 11)

Certament, els ritmes són trepidants i tot un repte per al tradicional pensament humanista i la seva forma de configurar-se. La següent opció és encara molt més perillosa i nociva, es tracta del derrotisme de la passivitat. Davant l'aparent inoperància dels esforços per tractar de continuar explicant de manera crítica com ens afecten els canvis tec- 
nològics, molts humanistes han renunciat a fer-ho directament, han triat el camí del silenci, davant un repte que sembla els supera, produint una desconnexió entre la tecnologia i el pensament humanista i social.

Per altra banda, és evident que la tecnologia en general i les tecnologies digitals en particular, estan molt connectades amb els ritmes que imposa el sistema capitalista. En aquest punt no se sap ben bé si les tecnologies estan al servei del capitalisme o és el capitalisme el que es va adaptant en funció dels avanços i els calendaris que aquestes marquen. Certament es tracta d'una relació molt complexa que genera una retroalimentació dins la qual, les problemàtiques ètiques associades tant al capitalisme com a la tecnologia estan ben presents. El desafiament per a la creació de corrents de pensament és enorme al voltant d'aquestes relacions. Els humanistes tracten de respondre al repte amb la creació de corrents de pensament que es posicionen tímidament d'una banda, de manera apocalíptica per altra, o bé s'alineen a aquesta idea, que encara es manté viva, de la tradició del progrés il-limitat i la confiança absoluta en la raó i l'ésser humà per a resoldre les problemàtiques que se li presenten. La renovada i sempre present dialèctica dels apocalíptics i els integrats (Eco, 1984). Una dialèctica que podríem exemplificar amb autors como ara P. Virilio (1997) o H. Jenkins (2008) en una i altra posició; o amb el relat que construeix el llibre Qué haremos cuando las máquinas lo hagan todo de M. Frank, P. Roehrig y B. Pring (2018). També està I'opció del silenci, al que ja ens hem referit, i que de vegades respon més bé a la incapacitat per construir respostes o generar nous interrogants.

Davant aquest desafiament, el pensament humanista tradicional sembla no respondre amb la celeritat i flexibilitat requerides. Existeix, no obstant, un altre model de creació de pensament i de construcció de coneixement, que també és en definitiva una nova forma de pensament humanista. Es tracta d'allò que les arts, les pràctiques artístiques i la creació de coneixement que generen accions vinculades a l'educació artística poden aportar en aquest encreuament de relacions complex. Alguns estudis vinculats a l'educació cognitiva situen precisament les arts en el centre d'un model d'integració de coneixements, en una posició privilegiada per a jugar aquest paper de mediació entre les Ciències Físiques i Tecnològiques, les Ciències Socials, la Història i les Humanitats afirmant que: «los lugares en que la integración del conocimiento se maximiza dependen de las obras de arte como claves para la comprensión. Esto también sugiere que las artes deberían estar centradas en el currículum en cuanto ámbito que intersecciona con los demás.» (Efland, 2004, p. 221)

Les arts en general i l'educació a través de les arts en particular, implica una forma d'interacció i interconnexió amb la resta del coneixement científic i humanístic. Esdevé per tant, com la candidata perfecta per assolir un nou ventall de relacions i de creació de nous pensaments en relació a les noves tecnologies. Podem posar per cas, per començar amb aquest plantejament, l'experiència del disseny. El disseny, que cal reivindicar com una clara expressió artística, s'articula i es connecta amb les noves tecnologies, especialment les tecnologies digitals i certament també amb el mateix sistema social i econòmic. El disseny genera connexions entre la tradició artística i els nous mitjans digitals i es configura com a una forma de creació de pensament complex en si mateix.

A través del pensamiento imaginativo el diseño elabora una nueva forma de relación con el entorno, con la realidad y con los objetos. Pero va más allá, porque establece vías, metodologías sistematizadas de trabajo para llevar los procesos imaginativos a un nivel más avanzado, como el que implica el tratar 
de adaptar a unas necesidades y limitaciones específicas los procesos creativos elaborados inicialmente en el pensamiento. (Ramon, 2018, p. 53)

D'aquesta manera, la vinculació que els dissenyadors tenen amb les noves tecnologies ens pot servir com punt de partida per a un replantejament de la forma de crear pensament i coneixement a través d'aquestes. Un replantejament sobre la forma de construir anàlisi crítica en relació a elles. Es tracta més bé de passar a construir discursos sobre les tecnologies, a crear discursos amb les tecnologies i a partir d'elles, que generen canvis de relació i construcció de noves possibilitats d'interpretació del món. Així, els dissenyadors per exemple, articulen a partir dels seus dissenys una nova forma d'interpretar el món, mitjançada per les tecnologies, que a la vegada és també un discurs sobre el paper d'aquestes en el món. Moltes vegades un discurs crític, que fins i tot desafien la mateixa funció d'aquestes amb l'estructuració materialitzada de pensaments complexos que implica el treball del disseny.

Si posem per cas la influència de les noves tecnologies en el desenvolupament de l'actual situació de crisi i emergència climàtica i ecològica que patim, precisament posem tota l'esperança en aquestes per tal de tractar de solucionar la situació sense que suposi un canvi dràstic en els nostres modes de vida. Una qüestió realment complexa i difícil a la que a hores d'ara sembla que no podem donar resposta. La mentalitat derivada de la modernitat i de la confiança en el progrés tecnològic illlimitat és la responsable directa d'aquesta situació, probablement per la falta d'una resposta teòrica contundent per part del pensament humanista cap a les revolucions tecnològiques i les seves implicacions. Unes tendències centrades en la fe i l'esperança en les capacitats de sols un model concret de pensament per resoldre i gestionar les problemàtiques a les quals ens enfrontem. Això ha menystingut en excés el poder d'altres formes de pensament vinculades a aspectes experiencials, emocionals o simbòlics, com ara, les que s'articulen a través de les formes d'expressió i pensament artístic.

Una resposta nascuda des d'un pensament sensible, simbòlic i creatiu pot construir una resposta empàtica, més d'una, amb el món en tota la seva complexitat. Mediada per les noves tecnologies, podrà encetar o completar amb èxit els processos de disseny, de re-disseny necessaris per poder sortir amb èxit d'aquesta terrible crisi. I és ací on entra en joc de manera clara el paper que l'educació artística ha de tindre en el re-disseny i en la forma de construir nous espais de relació reflexiva, creativa i estètica. Espais entesos com a transformadors, amb intersecció permanent amb les noves tecnologies, per plantejar relats superadors dels discursos de la modernitat, inclús de la postmodernitat.

Tornant de nou al relat de les connexions entre el pensament humanista i els avanços tecnològics, ens situem davant l'aparent desesperança en la qual ens havíem quedat i la dualitat d'opcions a les quals s'enfronta el pensament humanista. Potser hem de començar a abordar aquesta relació davall el prisma d'un pensament sensible, un pensament artístic i estètic que redirigeixi per complet la forma d'interpretar, d'usar i de gestionar la tecnologia i les noves cultures digitals perquè comencen a estar verdaderament al servei d'un pensament humanista transformador. Trencar amb la dinàmica del present dins la qual el pensament humanista està imbuït de tecnologia o és directament antitecnologia, i passar a concebre la tecnologia com a un producte de pensaments complexos creatius i artístics també. Interpretar-la com un mitjà en si mateix per a produir pensament humanista amb llenguatges i medis artístics. 
I dins el món general dels desenvolupaments tecnològics i les seves capacitats per a reinterpretar i comprendre el món, l'aliança que cal establir amb la tecnologia de cara a afavorir un pensament i un coneixement humanista, és precisament i com hem constatat, amb les arts. Les arts, associades a nous usos de les innovacions tecnològiques, converteixen a aquests en uns aliats del coneixement més complex que requereixen les arts i les humanitats a un nivell cognitiu. Tal com escrivia també el mateix Arthur Efland (2004):

Cuando los estudiantes construyen su conocimiento con conceptos tan excesivamente simplificados, no están preparados para los tipos de cuestiones complejas con las que probablemente se encuentren en niveles más avanzados de aprendizaje, jo en la propia vida! A menudo se considera que las representaciones bien estructuradas del conocimiento son más fáciles de enseñar y aprender, y por ello los libros de texto tienden a favorecerlas. En efecto, esto tergiversa la complejidad inherente (falta de estructuración) del aprendizaje en muchos campos, entre ellos las artes y las humanidades. (p. 28)

És a dir, en ocasions la tecnologia aplicada a usos educatius, acaba per produir discursos encara més simplificats que els mateixos llibres de text. Fins i tot, s'acaba per traslladar i convertir els llibres de text, quasi de manera calcada, en llibres electrònics i on tot està pensat per tal de fer més fàcil i en aparença més comprensibles els continguts educatius que es volen treballar. Però això, que pot resultar certament un avantatge pel que fa a determinades matèries, no resol en absolut la complexitat inherent al coneixement associat a les arts i les humanitats.

A més a més, alguns estudis conclouen, pel que fa a l'ensenyament universitari que la incidència d'aquestes tecnologies no és únicament incorrecta, sinó especialment escassa, concloent que hi ha una:

Escasa presencia que este tipo de medios tienen en los centros de enseñanza.

Nula tendencia de los profesores a diseñar y producir los materiales necesarios para el uso de este tipo de tecnologías.

En relación con los alumnos un elevado índice de desconocimiento tecnológico y baja capacidad para el análisis crítico y goce estético de las nuevas tecnologías. (Maroto Sánchez, 2007, p. 64)

Especialment l'última de les conclusions citades és la més rellevant pel que fa a l'anàlisi que desenvolupem en aquest article. La baixa capacitat que els estudis atribueixen a l'alumnat respecte a una postura crítica davant aquestes tecnologies digitals i la falta de capacitat de connexió, d'apreciació estètica davant aquestes. Que precisament un treball que posa el focus en l'ús de les tecnologies en les aules universitàries, consideri aquest fet tan rellevant, és un indicador de la importància que les arts tenen, com a constructores de l'experiència estètica sensible més intensa i productiva que existeix. Tant en la comprensió i interacció amb la nova cultura digital com en la comprensió més global i profunda del món contemporani.

Som conscients que les tecnologies també poden afavorir la creació de pensaments complexos, plens de les diversitats i matisos que la construcció d'un coneixement humanista i artístic requereix, per tal de ser efectivament útil com a mitjà pedagògic en aquests àmbits. I precisament, des de la nostra posició, això es pot fer efectiu especialment per mitjà de les arts. Continuem ara analitzant la forma en la qual les arts, com a creadores de pedagogies visuals a través de la fotografia, i en connexió necessària amb les noves tecnologies, suposen un instrument essencial per afavorir la creació de noves formes de coneixement vinculades al pensament humanista. 


\section{Clac! Clic! Touch! O la història del estats d'interacció amb la creació de la imatge fotogràfica}

Al llarg de la història de la humanitat, l'ésser humà ha fet servir quasi des de sempre mitjans tecnològics al seu servei, com a forma primària de desenvolupament i supervivència. I associat a aquests desenvolupaments tecnològics i culturals, des d'un principi, ha fet servir formes de construcció i representació simbòlica. És a dir, l'exemple paradigmàtic de les pintures rupestres confirma que almenys des de fa milers d'anys, quasi des que els humans hem utilitzat algun tipus de tecnologia, hem començat també a produir art a través de la creació d'imatges. Un tipus de representació que en termes absoluts continua tenint una continuació conceptual i simbòlica amb el seu correlat contemporani. La imatge ha esdevingut probablement al llarg de tota la història i evolució de la humanitat, l'element simbòlic per excel-lència, i és precisament la construcció i interpretació simbòlica la que es constitueix com a una de les formes d'aprenentatge més importants que té l'ésser humà des de quasi la creació de la cultura.

I la imatge, també des de sempre, ha estat connectada a les expressions artístiques, tal com hem vist. La creació, consum i producció d'imatges no s'entén històricament si no va en conjunt amb la mateixa història de l'art i així ve corroborat per aquesta. Si ens retrotraiem a l'època moderna pel que fa a l'evolució de la imatge, hi ha un fet inqüestionablement important que és l'aparició de la fotografia. La invenció de la fotografia sempre ha estat vinculada a les arts plàstiques, i en connexió directa amb la pintura, això és un fet històricament innegable i que també tindrà conseqüències en la vinculació permanent i constant entre les dues formes de representació simbòlica, com va demostrar de manera molt acurada John Berger (2007).

Amb l'aparició de la fotografia, especialment amb la seva popularització a través d'artefactes tecnològics com ara els desenvolupats històricament per marques de referència en el sector com ara Leica o Kodak, vam assistir a una revolució cultural sense precedents i que continua en el present de manera ben viva. La fotografia començava a fer-se popular i es democratitzava d'alguna manera la capacitat de creació d'imatges. Evidentment amb totes les limitacions que imposa la mateixa tecnologia i que també analitzarem. El medi fotogràfic esdevé així en un mitjà extens i universal de representació simbòlica dins les societats occidentals que quasi s'ha convertit en una prolongació del pensament. Primer a través del nostre braç, la nostra mà fins a arribar de manera quasi natural a tocar suaument amb el dit el dispositiu tecnològic de creació d'imatges que a hores d'ara són els smartphones. Aquests dispositius esdevenen prolongacions i conformadors de la nostra visió cultural del món, constructors i mediadors de cultura i de la creació de coneixements. D'una manera o una altra i amb totes les seves potencialitats, limitacions i problemàtiques múltiples que no són poques.

Així, arribem a aquesta evolució tecnològica que ha anat configurant la creació i ús de les imatges fotogràfiques i que hem sistematitzat i definit com a tres moments o èpoques. Hem emprat una referència onomatopeica, batejant-los com: Època del clac, època del clic i època del touch. No hem trobat una onomatopeia adequada per al silenci que implica el fet de fer una fotografia sense cap mediació mecànica i hem decidit utilitzar el terme anglosaxó de touch a tal efecte com a millor definidor d'aquest fet.

La fotografia naix associada a una tecnologia mecànica, en referència als aparells i mecanismes que permetien i continuen permetent el registre i la captura d'imatges. Des 
del vessant que ens interessa, la fotografia naix com a concepte de representació i espai constructor d'imaginaris culturals, quan deixa de ser un àmbit exclusiu de professionals i es posa a disposició d'una part important de la població la possibilitat de ser creadors i generadors de les seves pròpies imatges. En aquesta primera fase, l'època del clac, el soroll de l'impacte mecànic accionat per l'autor de la fotografia, activava tots els mecanismes possibles per capturar la imatge. Obrir l'obturador, deixar passar la llum el temps necessari per a registrar de forma física en una pel-lícula química una sèrie de trets, que amb els processos posteriors de revelatge i positivat donaria com a resultat una imatge fotogràfica.

En qualsevol cas, aquest procés que popularitzà l'ús de la fotografia i que naix inicialment arrelat al sistema capitalista de producció i consum, tindrà unes conseqüències revolucionàries que, a hores d'ara, no han estat suficientment analitzades i valorades en tota la seva amplitud i complexitat. Conseqüències que s'imbriquen directament amb qüestions pedagògiques, perquè des d'aquell moment, una gran part de la població començarà a tenir la possibilitat de disposar, a través d'un mitjà tecnològic, de construir la seva pròpia representació del món d'una manera a la qual fins ara havia resultat impossible. La pintura era cosa d'uns pocs experts, i els més afortunats comptaven amb la capacitat d'escriure, que ja estava consolidada en la major part de la població en aquell moment, com a forma primària de construir les seves pròpies representacions del món, en el context ampli del concepte, de forma sistematitzada i estructurada formalment.

És a dir, per primera vegada, es tenia a l'abast un medi, i com a medi, un mitjà de mediació simbòlica del món i tot el que això implica en la construcció del coneixement i l'aprenentatge, que era completament revolucionari. Un medi que implicava de forma inevitable una forta càrrega estètica des del seu naixement, que es connectava dins l'imaginari col-lectiu, també de manera inevitable amb la pintura, com a la forma de representació simbòlica del món per excel·ència en la construcció d'imatges fins a eixe moment. La imatge com a tal, com a concepte, és complexa en si mateixa, una síntesi abstracta, matèrica, amb relacions múltiples que van de la llum, el color, la textura, la composició, el grafisme, etc., per acabar per configurar a través de la interrelació de totes aquestes qüestions, una interrelació molt complexa. De fet, un constructe simbòlic i significatiu que ens permet aprendre i comprendre el món com cap altre medi ha aconseguit fins ara.

La imatge, com a síntesi abstracta que és, per molt que en aparença sembli representar una suposada realitat, acaba resultant més pedagògica, més adequada per a fins educatius que la mateixa realitat en si mateixa. Un exemple molt clar, ens resultaria impossible entendre el poc que sabem del funcionament de l'univers, o el mateix concepte de planeta terra, de no ser per la mediació simbòlica i abstracta de les imatges que ens representen tot això. Fins i tot amb aquestes ens costa aquesta aprehensió del que implica el mateix concepte de l'univers, sense aquestes el concepte i la realitat ens superaria i ens provocaria una indefensió total i aclaparadora de la qual no podríem eixir en tractar de comprendre-la.

Això ens dóna una idea molt clara de les implicacions pedagògiques directes de la imatge fotogràfica des d'aquesta primera època tecnològica de la seva aparició, que hem batejat com el període del clac. Una revolució per al desenvolupament del pensament 
humà sense precedents, que es posava a l'abast de tothom d'una manera tan increïblement senzilla, que des d'un primer moment es va convertir en una extensió del pensament humà en relació a la representació d'aquest món.

L'aparició de la fotografia, associada a les tecnologies que la fan possible, va esdevindre una revolució cultural que va anar transformant a poc a poc la forma en la qual els humans ens representàvem el món, l'exploràvem i el compreníem, incidint en la mateixa estructura mental i col-lectiva. I ho va fer fins al punt que a hores d'ara resulta difícilment imaginable un món sense el paper de la fotografia. Resulta encara més difícil imaginar-se el món sense el referent visual permanent de les imatges fotogràfiques que han anat construint la nostra imatge del món i han esdevingut en un mitjà de mediació i d'aprenentatge essencials. Però també i especialment de nosaltres, de les nostres semblances i diferències, un mitjà d'exploració del nostre cos, de les nostres pors, dels nostres desitjos, etc. En definitiva el període de la història del món que ens ha tocat viure no es pot descriure de cap manera si no és per mitjà de les aportacions que la imatge fotogràfica ha dut a terme, per a bé o per a mal.

Aquesta revolució que ja hem identificat que va començar amb l'època del clac, va anar un pas més enllà amb l'aparició dels primers avanços tecnològics que van possibilitar la creació de la fotografia digital. Això donà lloc a una segona època, pel que fa a la revolució cultural de la fotografia que bategem com a època del clic. Amb l'aparició de les primeres càmeres que permetien la captura i registre d'imatges a partir d'un sensor digital, s'estableix un pas més en aquesta evolució de la imatge fotogràfica. Un tipus de fotografia que no implica tan sols una diferència tecnològica amb el model clàssic de fotografia analògica, tal com analitzem en el següent apartat. Es tracta d'un nou tipus d'imatge de fet, que conceptualment i culturalment té unes implicacions i unes conseqüències que porten al fet que aqueixa primera revolució cultural que arribà amb la fotografia analògica, es posicionarà en una nova dimensió.

En un primer moment l'impacte cultural de la fotografia digital serà relativament tímid, i durant molt de temps s'establirà un període de transició en l'ús majoritari d'ambdues tecnologies. Podem definir per tant l'època del clic, amb una sèrie de característiques, pel que fa al seu impacte cultural. L'aparició d'aquestes primeres càmeres digitals implica un canvi de relació amb la producció i consum de les imatges fotogràfiques. Aquesta va provocar una multiplicació de les imatges produïdes. Per primera vegada en la història de la humanitat, una part important de la població tenia al seu abast de nou una nova tecnologia que permetia la creació d'un nombre d'imatges quasi il.limitat, multiplicant així també la capacitat i les possibilitats de visualització del món. Aquesta nova època de relació amb les imatges, no obstant això, estava també determinada per la necessitat d'una evolució en paral.lel amb la microinformàtica i la popularització dels ordinadors personals com a mitjà de treball i d'oci i, cada vegada més, espai de creació cultural digital. Aquestes càmeres digitals requereixen el suport de l'ordinador i les pantalles per a la visualització i emmagatzematge de les imatges, el que també canviarà les relacions socioculturals vinculades a l'ús social de la imatge fotogràfica dins la llar.

Les imatges del món i especialment les imatges dels micromons vinculades a les experiències personals s'amplien d'una forma sense precedents. En aquesta segona fase tampoc trobem una anàlisi profunda ni una recerca centrada a comprovar l'impacte cultural d'aquestes imatges en la forma de pensar el món i sobre el món, més enllà d'una aproximació més crítica i vinculada quasi sempre a l'impacte de les imatges produïdes i 
difoses pels mitjans de comunicació de masses i elaborades per professionals. Un dels pocs treballs que analitza l'impacte de les imatges produïdes de forma quotidiana i no professional és el llibre Un arte medio (Bourdieu, 2003).

L'última de les etapes dins l'àmbit de la popularització de l'ús i la creació de les imatges fotogràfiques es vincula al moment present. Ve derivat especialment de la incorporació de la càmera fotogràfica com a l'element més important dels dispositius tecnològics més rellevants de la cultura, els modes de vida i les interaccions socials contemporànies com són els smartphones. Aquest dispositiu no s'entén sense el paper de la càmera fotogràfica digital en interacció amb tot un ventall d'aplicacions subsidiàries, que en la seva major part giren al voltant de la imatge fotogràfica o el seu derivat, el vídeo. La mateixa configuració dels dispositius, que són en essència una pantalla que prioritza la imatge per damunt de qualsevol altra cosa, i el paper cada vegada més important que els mateixos fabricants li donen a la càmera, demostren que és un dispositiu essencialment fotogràfic o producte de la imatge fotogràfica digital.

Amb l'època del touch, entrem en una dimensió encara més multiplicadora de l'impacte de la creació i producció de fotografies en el món, que està fins i tot la responsable directa de noves formes de relació social, especialment entre els més joves (Bañuelos, 2017). Ens trobem de nou, en un escenari de buit analític, dins eixa complexa impossibilitat de donar resposta des de la literatura i la reflexió crítica del pensament humanista a l'evolució d'aquestes tecnologies i els seus impactes en la mateixa cultura i el pensament. Estem davant un moment on ara sí, la fotografia està a l'abast de tothom, pel que fa a la producció d'imatges pròpies, i on la fotografia juga un paper únic i essencial en la mateixa construcció del pensament del món, de qui som nosaltres i com ens definim davant el món, etc. De fet, quasi tota, per no dir tota la construcció i producció cultural del món està directament o indirectament associada a la pràctica de la fotografia o de la imatge.

D'aquesta manera, la tecnologia, la cultura, l'art i l'educació han estat sempre connectades al servei del desenvolupament humà, més encara en la societat i la cultura contemporànies. No es pot per tant deslligar l'anàlisi de les tecnologies digitals en referència a la cultura, de l'anàlisi de l'ús i evolució de la fotografia. Totes dues són quasi una mateixa cosa, la fotografia estimula i provoca avanços tecnològics alhora que aquests provoquen canvis i transformacions en la imatge fotogràfica, que finalment impacten de manera decisiva en tots els processos de coneixement del món que té l'ésser humà i especialment en els seus processos d'aprenentatge.

Ens queda per tant analitzar en aquest article les experiències fotogràfiques i el seu impacte en la construcció d'experiències d'aprenentatge del món, mitjançades a través de les arts i de l'experiència estètica i la forma en la qual finalment la fotografia esdevé com a un mitjà tecnològic per a la construcció de pensament.

\section{Tecnologies al servei de diferents tipus d'experiències fotogràfi- ques}

La narrativa de recerca de la qual parteix aquest text, se centra especialment en la fotografia i en les indagacions que a través del pensament i la reflexió d'escenaris i pràctiques pedagògiques es poden construir basant-se en ella, en interacció amb les arts i la tecnologia. Però també centrem el nostre interès en l'experiència de la pràctica de la fotografia i les formes de fer fotografia. És a dir, l'experiència de l'exercici i del fet fotogràfic actiu, i 
de les experiències de recepció visual i estètiques posteriors, mitjançades per la tecnologia. La influència de l'acció fotogràfica està present de forma molt notable en els processos de recepció estètica posteriors.

Com afirma de forma molt contundent Dubois (2015, p. 17): «Todo dispositivo implica una forma de pensamiento, esta es una de sus condiciones de existencia» i com continua reflexionant Lévy (2007, p. 9): «las mismas técnicas pueden integrarse en conjuntos culturales muy diferentes». S'estableix per tant la necessitat de continuar el nostre relat analític i discursiu a partir de l'anàlisi sobre els dispositius tecnològics associats a la pràctica i l'experiència de la fotografia. La fotografia és essencialment i de forma primària una construcció o un producte tecnològic de registre lumínic, tant en la seva versió analògica o química com en la seva faceta digital. En tots dos casos, es requereix la mediació d'un artefacte tecnològic, la càmera fotogràfica, per a la seva producció. Aquest fet, la necessitat d'una mediació tecnològica contundent sense la qual la fotografia no pot existir de cap manera, converteix aquest mitjà, en un medi de desenvolupament artístic de caràcter profundament tecnològic.

La fotografia naix per tant com a esdeveniment tecnològic en totes les seves formes d'expressió i des del primer moment del seu naixement, com també tots els medis que s'han derivat d'ella com el cinema i els audiovisuals. És a dir el gros de la cultura i les interaccions humanes contemporànies se li deuen a l'aparició d'aquesta tecnologia, però especialment a l'ús com a mitjà artístic i cultural que els humans li hem donat. Li hem atorgat un valor simbòlic i humanístic de primera magnitud, sense el qual no podria haver-se desenvolupat fins arribar a monopolitzar els sistemes d'intercanvi sociocultural del present.

Analitzant per tant les dues principals formes de producció d'imatges fotogràfiques, podem extraure alguns aspectes que influeixen de manera directa en la forma en la qual la fotografia i la tecnologia que la fa possible en cada cas, esdevingui una experiència d'aprenentatge i de creació de coneixement.

En el primer cas, el de la fotografia química, la càmera actua a través dels mecanismes que cada model estableix, en funció dels objectius o òptiques utilitzades, fins i tot en el cas de sistemes senzills com el de la fotografia pinhole, sense necessitat d'òptica, més enllà d'un mínim orifici que deixa entrar la llum necessària per a ser registrada. El registre es produeix de forma física, en el cas de la fotografia analògica sobre la pel-lícula i el suport químic que aquesta posseeix. Aquesta és diferent en funció del tipus de pel.lícula, color, blanc i negre, diapositiva, i totes les seves variants i formules que cada fabricant aplica. En aquest cas, una vegada produït el procés de revelatge i fixació, la imatge es materialitza literalment i per tant és un objecte físic, això té unes implicacions filosòfiques i vinculades a la pràctica i a l'experiència fotogràfica inqüestionables.

En el cas de la fotografia digital, és un sensor digital el que s'encarrega de traduir la captació de la llum, i del color, en un arxiu digital, i per tant un arxiu d'informació que els sistemes informàtics interpreten i converteixen en una imatge, utilitzant el programari de visualització adequat. En qualsevol cas, es tracta sempre d'un registre immaterial, emmagatzemat lògicament en un suport físic, targeta de memòria, disc dur, etc. Però en cap cas produint un objecte físic material, com sí produeix la fotografia analògica, sinó un arxiu d'informació que en última instància és un arxiu de codi que és interpretat com a imatge. 
La fotografia digital continua sent deutora absoluta de la fotografia analògica i de les formes de funcionament d'aquesta, fins al punt que fins i tot en els estàndards de la grandària dels sensors digitals, es continua utilitzant el concepte de full frame, o quadre complet per a les càmeres digitals més avançades que imiten la grandària del quadre de la pel-lícula de $35 \mathrm{~mm}$ utilitzat en la fotografia analògica. De la mateixa forma que succeeix amb les càmeres digitals de format mitjà, que imiten el model de les càmeres de pel.lícula de $120 \mathrm{~mm}$.

No obstant això, hi ha moltes diferències conceptuals i de grans implicacions filosòfiques entre tots dos mons de producció, creació i recepció d'imatges. D'una banda, «desde el punto de vista de lo digital, no hay diferencia entre un texto (un libro, un manuscrito, el grafismo), una imagen (pintura, fotografía, film, video, etc.) y sonidos (ya se trate de voces, de música o de ruidos). Todo es reducido a la base 'informática' de las data, en el mismo sustrato de las señales codificadas digitalmente» (Dubois, 2015, p. 24). Aquesta és una característica essencial de la imatge digital, que és en realitat un arxiu digital i la fotografia com a tal no té una essencialitat concreta diferenciada respecte a la de qualsevol altre tipus de dades informàtiques per al processador.

Per tant, pel que fa a la imatge digital, aquesta sempre va connectada al fet que es tracta en principi d'informació textual codificada i interpretada que es mostra com a conformadora d'una imatge. Un fet suggeridor en sí mateix conceptualment.

No obstant aquestes diferències, el que fan és en realitat enriquir les possibilitats d'experimentació, creació i recepció de les imatges, en diferents nivells ampliant les capacitats d'un aprenentatge sensible, configurant així els diferents models tecnològics en relació amb les imatges com diferents opcions d'aprenentatges i interpretacions diverses sobre el món.

\section{La fotografia com a mitjà tecnològic d'aprenentatge al servei d'un pensament humanista i transformador}

La fotografia digital contemporània, en aliança amb els avanços tecnològics i les expressions i experimentacions artístiques, ha permès que qualsevol persona tinga a l'abast, d'una manera o altra, la fotografia artística com a un dels principals mitjans de desenvolupament cultural. Tal i com explica Zhang (2018):

Intelligent technology has chanced the convenience of photography and allows ordinary people to enjoy the photography art. The popularity of photography allows people to obtain the high-quality pictures, while the intelligent photography has also influenced people's photography psychology. These changes has had a great impact on the photographic culture. (p. 4)

Arribats a aquest punt, entenem que la cultura digital, o allò que també ve en anomenar-se com a humanitats digitals, és impensable sense la presència de dos fets que estan en les arrels d'un desenvolupament cultural vinculat a les noves tecnologies. Evidentment es tracta de la imatge en general i de la imatge fotogràfica en particular. Però sense oblidar que a més dels codis estrictament visuals que es creen per mitjà de l'univers de la cultura digital, no seria possible desenvolupar un coneixement sensible, en un marc de referències tan ample i amb un univers simbòlic propi i en constant definició com el que emana d'aquesta, sense la presència constant de l'experiència estètica.

El paper de l'estètica en l'aprenentatge i en la construcció i creació de les imatges és indiscutible. L'experiència estètica, sense la qual no és possible la creació artística i sense 
la qual la cultura digital esdevindria un espai buit, inconnex i incomprensible per a la major part de la humanitat, actua de mediadora al seu torn entre els desenvolupaments tecnològics i les arts. La tecnologia constitueix una estructura simbòlica tan complexa que resultaria quasi impossible la seva comprensió i els constructes culturals arrelen en un discurs i una narració coneguda i comprensible com són les arts. I ho fa precisament a través del seu correlat representat en la imatge fotogràfica i els seus derivats visuals i audiovisuals.

El desenvolupament de l'imaginari cultural que implica allò que nomenem com a cultura digital, seria impensable sense la construcció d'un imaginari visual d'una càrrega estètica que viatja en múltiples direccions i que es converteix en el fil invisible que uneix tota l'estructura. En el material imprescindible per dotar d'un sentit les dimensions del coneixement que naixen i es nodreixen en el magma de l'univers digital i tecnològic. Com ens recorda Bozal (2008, p. 48): «Las estéticas no son cualidades naturales, presentes en los objetos pero eventualmente desconocidas por ignorancia, son cualidades históricas, es decir, configuradas en la relación de sujeto y objeto, una relación cambiante». És a dir, l'estètica esdevé un instrument al servei de les nostres interaccions que ens permet fer comprensible allò que seria incomprensible, un mitjà al servei d'un aprenentatge del món. I quan ens referim a món, ho fem en un sentit ample i multidimensional del terme, més enllà de l'espai físic sobre el qual habitem inevitablement. Parlem dels mons que construïm i que ens permeten desenvolupar-nos com a éssers humans amb un pensament superior. Entre ells, els mons vinculats a la cultura digital. Tots ells són mons sensibles, simbòlics i múltiples (Goodman, 1990), que esdevenen el mitjà a través del qual creem connexions que ens permeten comprendre'ns a nosaltres en relació amb la resta i amb tots els objectes i matèries que configuren el nostre esdevenir.

Així doncs, des d'una perspectiva educativa, la tecnologia esdevé en un constructe simbòlic a través del qual elaborem representacions dels mons possibles, i ho fem principalment per mitjà de les arts, de l'experiència estètica i de les imatges. Tot això no deixa de ser una experiència que es vincula a un aprenentatge a través de les arts, que en realitat té una funció molt clara, comprendre el món en la seva complexitat i diversitat. «El principal objetivo de la enseñanza del arte es que los alumnos lleguen a entender los mundos sociales y culturales en los que viven. Estos mundos son representaciones creadas a partir de cualidades estéticas de los medios artísticos» (Efland, Freedman i Sthur, 2003, p. 125).

D'aquesta manera podem concloure, que la fotografia, des del punt de vista de la cultura contemporània, no s'entén sense el desenvolupament tecnològic, al mateix temps que aquest tampoc podria tindre una lectura humana de no ser per la fotografia $i$ que tot això està emmarcat en un espectre de comprensió del món i de creació de coneixement com són les arts.

\section{Referències}

Bañuelos, J. (2017) «Fotografía móvil y redes sociales: Prácticas de producción y socialización en jóvenes universitarios». Revista ICONO14 Revista científica de Comunicación y Tecnologías Emergentes, 15(1), p. 1-22. doi:10.7195/ri14.v14i2.999

Berger, J. (2007) Modos de ver. Barcelona, Gustavo Gili.

Bordieu, P. (2003) Un arte medio. Barcelona, Gustavo Gili. 
Bozal, V. (2008) El gusto. Madrid, Antonio Machado Libros.

Dubois, P. (2015) El acto fotográfico y otros ensayos. Buenos Aires, La marca editora.

Eco, U. (1984) Apocalípticos e integrados. Barcelona, Lumen.

Efland, A. D. (2004) Arte y cognición. La integración de las artes visuales en el currículum. Barcelona, Octaedro.

Efland, A. D., Freedman, K. i Sthur, P. (2003) La educación en el arte posmoderno. Barcelona, Paidós.

Frank, M; Roehrig, P. i Pring, B. (2018) Qué haremos cuando las máquinas lo hagan todo. Artificial Intelligence, Bots and Big Data. Madrid, Lid Editorial.

Goodman, N. (1990) Maneras de hacer mundos. Madrid, Visor.

Jenkins, H. (2008) Convergence Culture: La cultura de la convergencia de los medios de comunicación. Barcelona, Paidós.

Lévy, P. (2007) Cibercultura. La cultura de la sociedad digital. Rubí, Anthropos Editorial.

Maroto Sanchez, A. (2007) «El uso de las nuevas tecnologías en el profesorado universitario». Pixel-Bit. Revista de Medios y Educación, 30, p. 61-72.

Ramon, R. (2018) «El diseño como visualización del pensamiento, medio de aprendizaje y construcción del mundo». En R. Huerta, A. Alonso-Sanz i R. Ramon (Ed.), Investigary educar en diseño. València, Tirant Humanidades, p. 41-56.

Virilio, P. (1997) El cibermundo, la política de lo peor. Madrid, Cátedra.

Zhang, B. (2018) The Influence of Intelligent Technology on Photography Technology and Art. Proceedings from IOP conference series. Materials Science and Engineering. 
Intersecciones entre imagen, arte y tecnología para la construcción de conocimientos sensibles

Resumen: Este artículo desarrolla un análisis alrededor de las conexiones y las repercusiones históricas entre la imagen fotográfica y la evolución de las nuevas tecnologías de la información y la comunicación, con el fin de establecer la capacidad de la fotografía artística para crear pensamiento y conocimiento, y establecerse así en uno de los medios educativos más relevantes de la cultura contemporánea. Establece los posicionamientos del pensamiento humanista respecto a estas evoluciones tecnológicas y el papel de la fotografía artística como articuladora de pensamiento crítico alternativo al discurso textual. Analiza dentro de esa evolución histórica reciente la importancia de la fotografía en la misma evolución de la tecnología y los posibles impactos en la cultura contemporánea y en la configuración del pensamiento y el imaginario del mundo. Finalmente analiza la importancia y la conexión que la fotografía, en relación con la tecnología establece con las artes y la estética y el papel de esta última como articuladora de procesos de creación de conocimiento, a través de la imagen.

Palabras clave: Fotografía, educación artística, tecnología, humanidades digitales, pedagogías visuales.

\section{Intersections entre image, art et technologie pour la construction de connaissances sensibles}

Résumé: Cet article développe une analyse autour des connexions et des répercussions historiques entre l'image photographique et l'évolution des nouvelles technologies de l'information et de la communication, dans le but d'établir la capacité de la photographie artistique à créer une pensée et une connaissance, et à devenir ainsi l'un des moyens éducatifs les plus significatifs de la culture contemporaine. Il établit les prises de position de la pensée humaniste à l'égard de ces évolutions technologiques et le rôle de la photographie artistique en tant qu'outil d'articulation de la pensée critique alternative au discours textuel. II analyse, au sein de cette évolution historique récente, l'importance de la photographie dans l'évolution même de la technologie et les impacts possibles dans la culture contemporaine et dans la configuration de la pensée et de l'imaginaire du monde. Finalement, il analyse l'importance et la connexion que la photographie, en rapport avec la technologie, établit avec les arts et l'esthétique, ainsi que le rôle de cette dernière en tant qu'outil d'articulation de processus de création de connaissance, à travers l'image.

Mots clés: Photographie, éducation artistique, technologie, sciences humaines numériques, pédagogies visuelles.

\section{Intersections between image, art and technology for the construction of sensitive knowledge}

Abstract: This article analyses the historical connections and repercussions of the photographic image and the growth of new information and communication technologies. It explores the ability of artistic photography to promote thought and knowledge, and to position itself as one of the most important educational media in contemporary culture. It establishes the positions of humanist thinking regarding these technological developments and the role of artistic photography as a trigger of critical thinking, and an alternative to textual discourse. Focusing on this recent groundbreaking evolution, the article also studies the importance of photography in the advancement of technology itself and the possible impact on contemporary culture and on the configuration of thought and collective creativity in the world. Finally, it analyses the importance and the connection that photography, in relation to technology, has with the arts and aesthetics and the role of technology as a driving force behind processes of knowledge creation via images.

Keywords: Photography, arts in education, technology, digital humanities, visual pedagogies. 